\title{
Deteksi Pasien Obstetrik Kritis dengan Maternal Early Warning System
}

\author{
Ratih Kumala Fajar Apsari \\ Departemen Anestesiologi dan Terapi Intensif Fakultas Kedokteran, Kesehatan Masyarakat dan Keperawatan \\ Universitas Gadjah Mada-RSUP Dr. Sardjito Yogyakarta
}

\begin{abstract}
Abstrak
Adaptasi fisiologis yang terjadi pada ibu hamil dapat menyamarkan tanda-tanda penyakit maternal berat. Ini mempersulit identifikasi kolaps maternal yang akan terjadi. Penggunaan early warning system (EWS) yang dimodifikasi untuk penggunaan pada pasien ibu hamil dan postpartum akan membantu dalam identifikasi, treatment dini, dan penanganan pasien yang memiliki, atau akan mengalami, penyakit kritis. Maternal Early Warning System (MEWS) seharusnya mengidentifikasi pasien yang berisiko untuk mengalami perburukan pada saat intervensi dini dapat mencegah perburukan ke morbiditas berat MEWS telah digunakan secara ekstensif dalam praktek obstetrik, tetapi sistem yang digunakan sangat bervariasi. Parameter-parameter yang sering dimasukkan dalam MEWS antara lain denyut jantung, tingkat pernapasan, tekanan darah, dan tingkat kesadaran. Dari berbagai MEWS yang telah dikembangkan, ada tiga MEWS utama, yaitu (1) modified early obstetric warning system (MEOWS), (2) Maternal Early Warning Criteria (MEWC), dan (3) Maternal Early Warning Trigger (MEWT) tool. Hingga kini masih belum diketahui sistem MEWS apa yang terbaik, dan setiap rumah sakit mungkin memerlukan penyesuaian dalam parameter MEWS. Literatur yang ada menunjukkan kemungkinan manfaat dan mendukung penggunaan MEWS. Implementasi dan penggunaan MEWT telah dikaitkan dengan penurunan morbiditas maternal komposit dan morbiditas maternal berat. Akan tetapi, respon apa yang optimal untuk setting tertentu agar memperbaiki pelayanan maternal setelah tanda peringatan muncul hingga kini masih belum jelas.
\end{abstract}

Kata kunci: early warning system; maternal; surveillance

\section{Detection of Critically Ill Obstetric Patients with Maternal Early Warning System}

\begin{abstract}
Physiological adaptations that develop in pregnant women may obscure signs of severe maternal diseases. These causes difficulties in identifying the impending maternal collapse. An early warning system (EWS) modified for pregnant and postpartum women may assist in identification, early treatment, and management of patients who already or will develop critical illness. Maternal Early Warning System MEWS has been extensively used in obstetric practices; however, the systems used in preactice are varied. The most considered parameters for MEWS are heart rate, respiratory rate, blood pressure, and level of consciousness. From many MEWS developed, three primary MEWS existed, (1) modified early obstetric warning system (MEOWS), (2) Maternal Early Warning Criteria (MEWC), dan (3) Maternal Early Warning Trigger (MEWT) tool. There is still no consensus regarding which MEWS is superior, and different hospitals may require adjustments in MEWS parameters. The existing literatures suggested the potential benefit of MEWS and supported MEWS in clinical practice. Implementation and adoption of MEWS had been associated with reduced composite maternal morbidities and severe maternal morbidities. However, the optimal response for certain settings to improve maternal services after warning system has been activated is still lacking.
\end{abstract}

Key words: early warning system; maternal; surveillance 


\section{Pendahuluan}

Penggunaan early warning system (EWS) untuk pasien telah dimulai sejak tahun 1999. Pada saat itu diketahui bahwa nilai fisiologis yang sangat menyimpang ditemukan pada banyak pasien dalam 24 jam sebelum admisi ke Intensive Care Unit (ICU) dari bangsal rumah sakit. Informasi yang diambil dari bangsal dapat mengidentifikasi pasien dengan penyakit serius yang mungkin akan mendapatkan manfaat dari intervensi yang lebih cepat dan disimpulkan bahwa seleksi pasien lebih dini dapat memperbaiki kemungkinan survival secara signifikan. ${ }^{1}$ Adaptasi fisiologis yang terjadi pada ibu hamil memastikan kelangsungan kehamilan, kelahiran dan pemulihan postnatal yang sehat. Akan tetapi, peningkatan cadangan kardiovaskular dan perubahan-perubahan fisiologis lainnya pada ibu hamil dapat menyamarkan tanda-tanda penyakit maternal berat. Ini mempersulit identifikasi kolaps maternal yang akan terjadi. Pasien ibu hamil dengan penyakit serius, khususnya sepsis, mungkin akan tampak dalam keadaan stabil, sebelum kemudian mendadak kolaps, sering kali hanya dengan sedikit peringatan atau tanpa peringatan sama sekali. Selain itu, kondisi maternal mungkin terganggu pada pasien ibu hamil dengan usia lebih tua, wanita obes, atau wanita dengan kondisi medis kompleks. Penggunaan EWS yang dimodifikasi untuk pasien ibu hamil dan postpartum akan membantu dalam identifikasi, treatment dini, dan penanganan pasien yang memiliki, atau akan mengalami, penyakit kritis. $^{2}$

Maternal early warning system (MEWS) adalah strategi surveillance yang dirancang untuk menjawab temuan dari berbagai tinjauan mortalitas bahwa respon klinis terhadap perburukan akut pada pasien obstetrik sering kali terlambat atau kurang. Sistem ini kini semakin diimplementasikan oleh leadership keamanan obstetrik. Penelitian di masa mendatang perlu memfokuskan pada memperbaiki parameterparameter dalam early warning system, strategi respon yang optimal dalam berbagai setting klinis, dan menciptakan instrumen pendukung untuk penatalaksanaan pasien berisiko tinggi. ${ }^{3}$
Early warning system untuk mendeteksi penyakit kritis pada pasien obstetrik telah dirancang secara spesifik untuk populasi ini karena (1) perubahan fisiologis yang terjadi selama kehamilan dan (2) sedikitnya jumlah kondisi yang bertanggung jawab atas sebagian besar morbiditas berat dan mortalitas maternal. Rekomendasi untuk penggunaan EWS memiliki sejumlah batasan yang tidak bisa diaplikasikan untuk pasien hamil. Adopsi sistem peringatan maternal direkomendasikan kuat dalam laporan Saving Mothers Lives tahun 2007 dari Confidential Enquiries into Maternal and Child Health (CEMACH) di Inggris. Laporan ini menyebutkan adopsi MEOWS berbasis rumah sakit sebagai rekomendasi "top ten", sebuah prioritas tertinggi "dimana setiap anggota komisi, penyedia layanan, pembuat kebijakan, dan stakeholder lainnya yang terlibat dalam layanan maternitas seharusnya membuat rencana untuk memperkenalkan, dan mengaudit, sesegera mungkin". Laporan CEMACH memasukkan tinjauan kasus tentang kematian maternal dan menemukan bahwa "dalam banyak kasus di dalam laporan ini, tanda perigatan awal untuk kolaps maternal yang akan terjadi tidak dikenali"., 3

\section{Tujuan Program}

MEWS dirancang untuk mempertimbangkan perubahan fisiologis normal yang terjadi selama kehamilan. MEWS dikembangkan untuk memperbaiki identifikasi ibu hamil yang berisiko untuk mengalami perburukan klinis dan memfasilitasi intervensi dini. Pemicu-pemicu dalam sistem MEWS secara teoritik menghasilkan identifikasi yang lebih dini terhadap sejumlah kondisi yang mungkin berkontribusi terhadap morbiditas dan mortalitas maternal. MEWS dimaksudkan untuk memandu penilaian klinis, dan bukan menggantikannya. ${ }^{5}$

MEWS adalah sebuah instrumen yang menjanjikan untuk mengurangi morbiditas dan mortalitas maternal. Untuk memperbaiki outcome kesehatan, MEWS seharusnya mengidentifikasi pasien yang berisiko untuk mengalami perburukan pada saat intervensi dini dapat mencegah perburukan ke morbiditas berat. ${ }^{6}$ 
Tabel 1. Modified Early Obstetric Warning System (MEOWS) ${ }^{3}$

\begin{tabular}{|c|c|c|c|}
\hline Parameter fisiologis & Nilai normal & Yellow alert & Red alert \\
\hline Tingkat pernapasan & $10-20 \mathrm{x} / \mathrm{menit}$ & $21-30 \mathrm{x} / \mathrm{menit}$ & $<10$ atau $>30 \mathrm{x} /$ menit \\
\hline Saturasi oksigen & $96-100 \%$ & & $<95 \%$ \\
\hline Suhu tubuh & $36,0-37,4 \mathrm{oC}$ & $35-36$ atau $37,5-380 \mathrm{C}$ & $<35$ atau $>38$ oC \\
\hline Tekanan darah sistolik & $100-139 \mathrm{mmHg}$ & $\begin{array}{l}150-180 \text { atau } 90-100 \\
\mathrm{mmHg}\end{array}$ & $>160$ atau $<90 \mathrm{mmHg}$ \\
\hline Tekanan darah diastolik & $50-89 \mathrm{mmHg}$ & $90-100 \mathrm{mmHg}$ & $>100 \mathrm{mmHg}$ \\
\hline Denyut jantung & $50-99 \times /$ menit & $\begin{array}{l}100-120 \text { atau } 40-50 \mathrm{x} / \\
\text { menit }\end{array}$ & $>120$ atau $<40 \mathrm{x} /$ menit \\
\hline Respon neurologis & alert & suara & Tidak merespon, nyeri \\
\hline
\end{tabular}

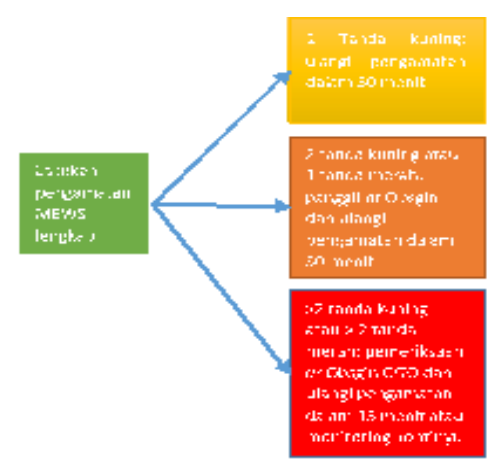

Gambar 1. Protokol Eskalasi MEOWS

MEWS yang optimal akan menghasilkan nilai positif palsu yang rendah. MEWS yang menghasilkan banyak positif palsu, bisa menjadi "nuisance alarm (alarm pengganggu)", memperburuk pelayanan pasien dan berkontribusi terhadap "alarm fatigue". Alarm fatigue terjadi ketika penyedia layanan medis terlalu terbebani dan menjadi terdesensitisasi oleh peringatan yang memiliki kegunaan klinis minimal atau tidak ada sama sekali (nuisance alarm) dan menjadi sumber terjadinya medical error. ${ }^{7}$

\section{Variasi Alert System}

MEWS telah digunakan secara ekstensif dalam praktek obstetrik, tetapi sistem yang digunakan sangat bervariasi. Parameter-parameter yang sering dimasukkan dalam MEWS antara lain denyut jantung, tingkat pernapasan, tekanan darah, dan tingkat kesadaran. Parameter-parameter lain seperti skor nyeri, karakteristik lochia dan output urin kadang dimasukkan, baik dalam bentuk skor atau dicatat dalam rekam medis. Sejumlah variasi MEWS, beberapa contoh diantaranya adalah Modified Obstetric Early Warning System (MOEWS), Maternal Early Warning Criteria (MEWC), Maternal Early Warning Trigger tool (MEWT), Irish Maternal Early Warning System (IMEWS), Obstetric Early Warning System (ObsEWS), ICNARC MEWS. ${ }^{6}$

EWS utama adalah: (1) modified early obstetric warning system (MEOWS) yang diajukan dari UK Saving Mothers' Lives Report, (2) Maternal Early Warning Criteria (MEWC) yang diajukan dari National Partnership for Maternal Safety, dan (3) Maternal Early Warning Trigger (MEWT) tool yang digunakan di Dignity Health System dan rumah sakit lain di Amerika Serikat. Pada MEOWS, dua parameter abnormal sedang (yellow alert) atau satu parameter abnormal berat (red alert) memicu respon klinis untuk memeriksa status pasien secepatnya dan membuat rencana surveillance follow-up. Parameter dalam MEWC merupakan sebuah EWS yang disederhanakan dari MEOWS. MEWT berbeda dari MEOWS dan MERC dimana instrumen ini mengelompokkan alert ke dalam pathway diagnostik untuk kondisikondisi seperti sepsis, kondisi kardiopulmonaris, kelainan hipertensi, dan perdarahan obstetrik, dan memberikan rekomendasi diagnostik dan manajemen berdasarkan parameter-parameter ini. Tabel 3 menunjukkan perbedaan utama antara MEOWS, MEWC, dan MEWT. ${ }^{7}$

MEOWS

Modified Early Obstetric Warning System (MEOWS) didasarkan pada obstetric EWS 
Tabel 2. Maternal Early Warning Criteria (MEWC) ${ }^{7}$

\begin{tabular}{ll}
\hline Kriteria & Nilai \\
Tekanan darah sistolik, mmHg & $<90$ atau $>160$ \\
Tekanan darah diastolik, & $>100$ \\
mmHg & \\
$\begin{array}{l}\text { Denyut jantung, kali per menit } \\
\text { Tingkat pernapasan, kali per }\end{array}$ & $<50$ atau $>120$ atau $>30$ \\
menit & \\
Saturasi oksigen, \% dengan & $<95$ \\
udara ruangan & \\
Oliguria, mL/jam $\geq 2$ jam & $<35$ \\
\hline
\end{tabular}

dari sembilan rumah sakit di Inggris. MEOWS ini diajukan oleh Confidential Enquiries into Maternal and Child Health pada tahun 2007. ${ }^{4}$

Di dalam sistem ini, 2 parameter abnormal moderat (tanda kuning) atau 1 parameter abnormal berat (tanda merah) memicu sebuah respon klinis untuk segera menilai status pasien dan membuat rencana surveillance follow up. Parameterparameter ini dirancang untuk mendeteksi pasien yang menderita kondisi yang dapat menyebabkan mortalitas dan morbiditas maternal berat (tabel 1). Parameter peringatan MEOWS dapat membantu mendeteksi kondisi-kondisi berikut yang mungkin tidak dikenali: perdarahan (ditunjukkan dengan hipotensi dan takikardia), sepsis (demam, hipotensi, takikardia, hipoksia), tromboemboli vena (takikardia, takipnea, hipoksia) preeklampsia (hipertensi, hipoksia), dan komplikasi kardiovaskular (takikardia, bradikardia, hipoksia, hipotensi).3 Gambar 1 adalah salah satu contoh protokol eskalasi intervensi ketika ada trigger pada ibu hamil. ${ }^{6}$

\section{MEWC}

Di Amerika Serikat, National Partnership for Maternal Safety, sebuah kelompok leadership nasional, mengusulkan sebuah early warning system yang disederhanakan dari MEOWS, yang disebut Maternal Early Warning Criteria (MEWC). Meski MEOWS memberikan sebuah sistem skoring sederhana, MEWC memberikan sebuah trigger system. ${ }^{8}$ Jika seorang pasien memiliki satu parameter abnormal (tabel 2), penilaian pasien secepat mungkin diperlukan. Parameter-parameter dalam MEWC dipilih untuk meminimalkan tingkat alarm palsu, memfasilitasi implementasi, dan mempertahankan sensitivitas, berdasarkan padatinjauan-tinjauankasuskematian maternal sering menunjukkan abnormalitas tanda vital yang jelas sebelum terjadinya penyakit kritis. Karena jenis rumah sakit yang beragam, dari rumah sakit komunitas non-pendidikan kecil hingga rumah sakit pendidikan rujukan tersier berskala besar, penentuan petugas dan respon protokol yang optimal untuk alarm adalah tanggung jawab dari masing-masing rumah sakit. Berdasarkan tipe layanan yang diberikan, alert response mungkin dipimpin oleh dokter obstetrik, anestesi, rumah sakit, dokter ICU, dokter UGD, atau sebuah rapid response team. Demikian pula, karena setting klinis yang beragam, variabelvariabel outcome dan langkah-langkah proses untuk sistem ini masih belum jelas. American Congress of Obstetricians and Gynecologists District II's Safe Motherhood Initiative, sebuah kolaborasi untuk memperbaiki outcome maternal di New York, negara bagian dengan salah satu tingkat mortalitas tertinggi, telah mendorong MEWC untuk digunakan di semua rumah sakit yang menyediakan layanan obstetrik. ${ }^{3}$

\section{MEWT}

Instrumen MEWT berbeda dari MEOWS dan MEWC karena MEWT dirancang untuk mengidentifikasi 4 dari penyebab utama morbiditas maternal, yaitu sepsis, disfungsi kardiovaskular, preeklampsia-hipertensi berat, dan perdarahan. Perbedaan lain dariMEWTadalah dimasukkannya rekomendasi untuk asesmen dan treatment pasien. Instrumen ini juga berperan sebagai pengingat bagi klinisi bahwa mungkin ada tumpang tindih dalam clinical pathway dan bahwa mungkin diperlukan asesmen terhadap lebih dari satu pathway. Mengikuti clinical pathway telah diketahui menurunkan kematian karena sepsis, menurunkan morbiditas karena preeklampsia berat, dan mengurangi morbiditas karena perdarahan. Dengan penggunaan clinical pathway ini, instrumen MEWT diharapkan dapat mempercepat asesmen dan treatment pasien. Asesmen dan intervensi oleh klinisi dapat dilakukan dalam waktu $<60$ menit pada $>$ 80\% pasien MEWT positif dan clinical pathway diikuti pada $>80 \%$ kasus. ${ }^{9}$ 


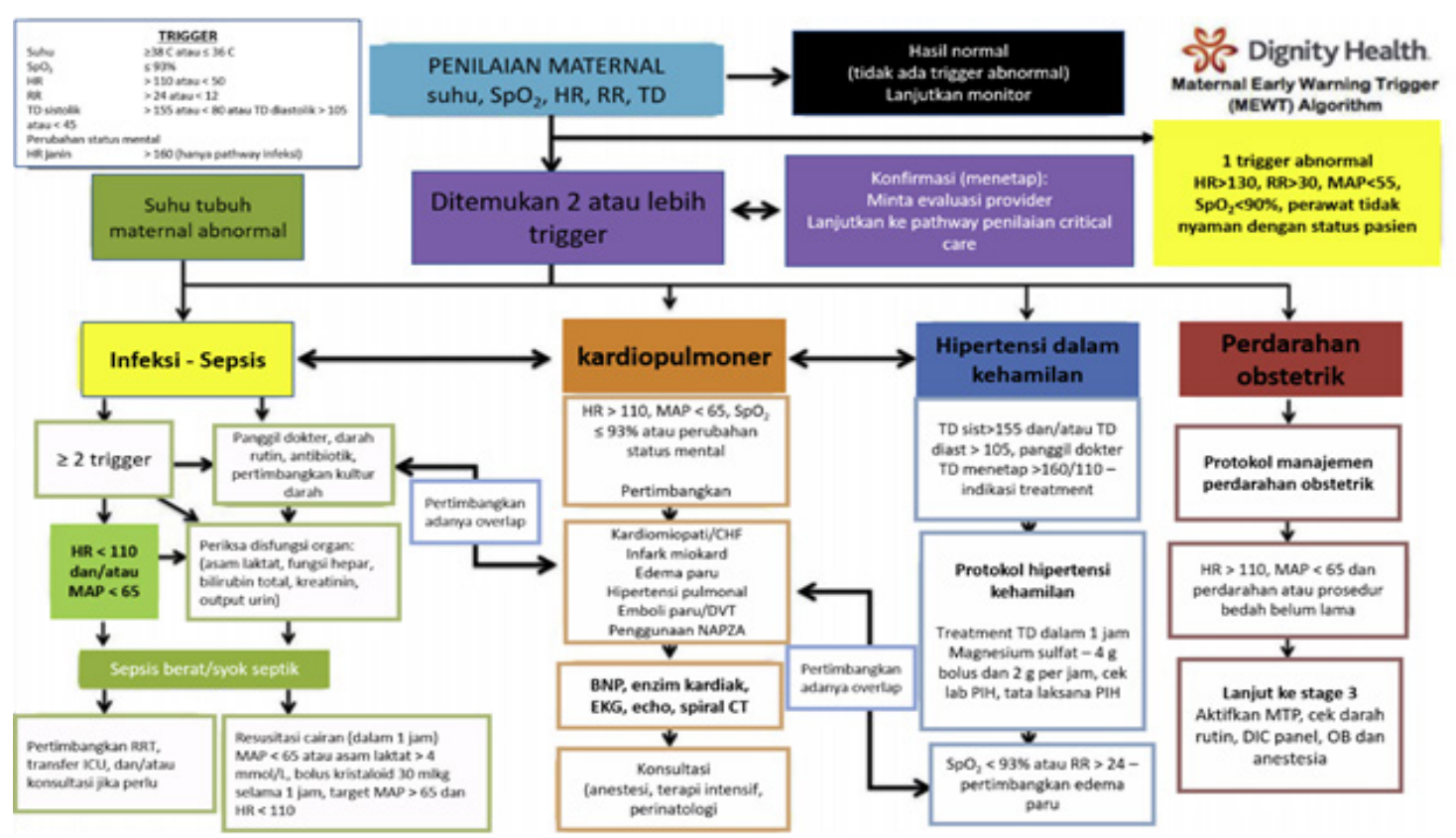

Gambar 2. Diagram alur Maternal Early Warning Tool (MEWT) ${ }^{9}$

Tabel 3. Perbedaan utama antara MEOWS, MEWC, dan MEWT ${ }^{7}$

\begin{tabular}{llll}
\hline & MEOWS & MEWT & MERC \\
\hline Kiteria untuk evaluasi & $\begin{array}{l}\text { Satu trigger "merah" } \\
\text { atau dua trigger "kun- } \\
\text { ing" }\end{array}$ & $\begin{array}{l}\text { Satu trigger "merah" } \\
\text { atau dua trigger "kun- } \\
\text { ing" } \\
\text { Tidak }\end{array}$ & $\begin{array}{l}\text { Satu trigger "merah" } \\
\text { (tidak ada trigger } \\
\text { "kuning") }\end{array}$ \\
$\begin{array}{l}\text { Panduan untuk sup- } \\
\text { port keputusan dan } \\
\text { eskalasi kondisi }\end{array}$ & & Ya, clinical pathway" & Tidak \\
$\begin{array}{l}\text { Data tentang karakter- } \\
\text { istik tes }\end{array}$ & Ya & Ya & \\
Data outcome & Tidak & Ya & Tidak \\
\hline
\end{tabular}

\section{Bukti Ilmiah}

Literatur yang ada menunjukkan kemungkinan manfaat dan mendukung penggunaan MEWS. Sebuah penelitian observasional prospektif pada tahun 2016 mengevaluasi MEWS dan menemukan bahwa $27 \%$ dari pasien memicu sebuah respon, dan $17 \%$ pasien memenuhi kriteria untuk morbiditas obstetrik. MEWS diketahui memiliki sensitivitas $86 \%$ dan spesifisitas $85 \%$ untuk memprediksi kemunculan morbiditas maternal. ${ }^{10}$ Meski penelitian-penelitian ini menunjukkan test characteristic yang memuaskan untuk MEOWS, mereka tidak menilai efikasi dalam hal (1) mengidentifikasi penyakit kritis yang tidak terdeteksi yang akan terjadi, (2) mengoptimalkan process measures dalam proses penatalaksanaan (seperti waktu hingga pemberian antihipertensi), atau (3) perbaikan dalam outcome yang bermakna secara klinis. ${ }^{7}$

Sebuah penelitian yang membandingkan nilai prediktif dari enam MEWS yang berbeda untuk mengidentifikasi sepsis berat pada pasien wanita dengan chorioamnionitis melaporkan rentang sensitivitas $40-100 \%$ dan spesifisitas 4-97\%. Penulis menyimpulkan bahwa instrumen MEWS dengan rancangan yang lebih sederhana cenderung lebih sensitif, sedangkan yang lebih kompleks lebih spesifik, dan menunjukkan diperlukannya penelitian lebih lanjut. ${ }^{11}$ Skor yang sederhana memiliki reliabilitas yang lebih baik, 
lebih tahan terhadap kesalaharan perhitungan dan memiliki reproduksibilitas yang lebih baik. ${ }^{6}$

Sebuah penelitian prospektif dilakukan di sejumlah lokasi dalam sebuah jaringan rumah sakit berskala besar memberikan bukti untuk MEWT. Implementasi dan penggunaan MEWT pada lebih dari 180.000 persalinan menunjukkan penurunan sebesar $14 \% \quad(p=0,001) \quad$ dalam morbiditas maternal komposit dan penurunan $18 \%(\mathrm{p}=0,01)$ dalam morbiditas maternal berat (berdasarkan definisi CDC). Secara keseluruhan, ada penurunan yang signifikan dalam morbiditas maternal berat yang didefinisikan menurut kriteria dari CDC dari angka 2,0\% pra-implementasi menjadi $1,6 \%$ pasca implementasi. ${ }^{9}$ Tingkat positif skrining jauh lebih rendah dengan MEWT $(2,3 \%)$ daripada dengan MEOWS. Perbedaan ini mungkin disebabkan karena (1) persyaratan parameter-parameter abnormal dalam instrumen MEWT untuk tetap ada sebelum memicu peringatan, dan (2) ambang batas yang lebih ketat untuk aktivasi dengan satu parameter. ${ }^{7}$

Pada tahun 2013, Intensive Care National Audit and Research Center (ICNARC) di Inggris melaporkan early warning scoring system untuk ibu hamil yang pertama kalinya tervalidasi secara statistik. Sebuah dataset admisi obstetrik ke ICU dianalisis dan ICNARC MEWS dibandingkan dengan MEWS yang sudah ada, dalam kemampuan mereka untuk memprediksi survival berdasarkan parameter fisiologis dalam 24 jam pertama setelah masuk ICU. ICNARC MEWS memiliki sensitivitas dan spesifisitas yang tinggi, dengan kurva AUROC 0.94 (95\% CI $0.88-$ 0.99). ${ }^{12}$ Bukti ilmiah yang ada saat ini mendukung pendapat bahwa parameter-parameter early warning mungkin berguna secara klinis untuk mengidentifikasi pasien yang nantinya menjadi kritis atau berisiko tinggi untuk kematian. Akan tetapi, data-data ini terutama berasal dari single center, dan diperlukan penelitian lebih lanjut untuk memperbaiki generalibilitas dan validitas. Untuk saat ini, belum ada data yang menunjukkan respon apa yang optimal untuk setting tertentu agar memperbaiki pelayanan maternal setelah tanda peringatan muncul. ${ }^{3}$

\section{Optimalisasi MEWS}

Maternal early warning system adalah sebuah strategi yang menjanjikan untuk menurunkan morbiditas berat dan mortalitas maternal. Agar sebuah maternal early warning system berkontribusi terhadap perbaikan outcome kesehatan, sistem ini harus (1) mengidentifikasi pasien yang berisiko untuk penyakit kritis dan yang akan mendapatkan manfaat dari intervensi dini dan (2) tidak menghasilkan banyak peringatan yang positif palsu sehingga penanganan pasien menjadi terganggu. ${ }^{3}$

Penentuan bentuk MEWS yang optimal memerlukan penelitian lebih lanjut. Penetapan sebuah MEWS terstandarisasi nasional mungkin akan memberikan data yang diperlukan untuk menganalisis dan memperbaiki parameterparameter untuk menghasilkan sensitivitas dan spesifisitas yang lebih baik. Akan tetapi, setiap rumah sakit yang berbeda mungkin akan mendapatkan manfaat dari penyesuaian parameter-parameter pemicu dan tindakantindakan yang sesuai tergantung pada sumber daya yang tersedia. MEWS hanyalah bagian dari penatalaksanaan pasien ibu hamil kritis. Outcome akan tergantung pada eskalasi penanganan dan penatalaksanaan yang tepat ketika ada pemicu MEWS. ${ }^{6}$ Setiap rumah sakit mungkin akan memerlukan protokol respon yang berbeda berdasarkan ketersediaan staf dokter, status rumah sakit pendidikan, jumlah tempat tidur, keahlian perawat, layanan konsultan, dan ketersediaan terapi intensif. Selain itu, identifikasi pasien yang berisiko tidak memastikan bahwa (1) pemeriksaan dan evaluasi diagnostik yang tepat akan dijalankan berdasarkan hasil skrining positif atau (2) bahwa dengan diagnosis yang tepat, intervensi yang dilakukan setelahnya akan sesuai. Karena morbiditas berat dan mortalitas maternal jarang, instrumen pendukung keputusan klinis mungkin menjadi komponen penting untuk memberikan respon yang optimal, khususnya di rumah sakit non-pendidikan kecil. ${ }^{3}$

Penghambat penting dalam implementasi maternal early warning system antara lain: ${ }^{7}$ tidak adanya koordinasi dan buy in multidisipliner, 
Pendidikan yang kurang, integrasi yang kurang optimal di dalam kultur dan praktek rumah sakit, kurangnya support dari leadership, kurangnya kesesuaian dengan inisiatif perbaikan kualitas dan keamanan lainnya

\section{Simpulan}

Maternal early warning system adalah strategi surveillance yang dirancang untuk mempertimbangkan perubahan fisiologis yang terjadi selama kehamilan dan persalinan. MEWS telah digunakan secara ekstensif dalam praktek obstetrik, tetapi sistem yang digunakan sangat bervariasi. Bukti ilmiah yang ada saat ini mendukung pendapat bahwa parameterparameter dalam early warning mungkin berguna secara klinis untuk mengidentifikasi pasien yang nantinya menjadi kritis atau berisiko tinggi untuk kematian. Akan tetapi, belum ada data yang menunjukkan respon apa yang optimal untuk setting tertentu agar memperbaiki pelayanan maternal setelah tanda peringatan muncul. Setiap rumah sakit mungkin akan memerlukan protokol respon yang berbeda.

\section{Daftar Pustaka}

1. Quinn AC, Meek T, Waldmann C. Obstetric early warning systems to prevent bad outcome. Curr Opin Anaesthesiol. 2016 Jun;29(3):268-72.

2. Confidential Enquiry into Maternal and Child Health. Saving Mothers' Lives: Reviewing maternal deaths to make motherhood safer: 2006-08. The Eighth Report on Confidential Enquiries into Maternal Deaths in the United Kingdom. London: CEMACH; 2011.

3. Friedman AM. Maternal Early Warning Systems. Obstet Gynecol Clin North Am. 2015 Jun;42(2):289-98.

4. Confidential Enquiry into Maternal and Child Health. Saving Mothers' Lives: Reviewing maternal deaths to make motherhood safer: 2003-04. The Seventh Report on Confidential
Enquiries into Maternal Deaths in the United Kingdom. London: CEMACH; 2007.

5. Knight M, Nair M, Tuffnell D. Saving Lives, Improving Mothers' Care - Surveillance of maternal deaths in the UK 2012-14 and lessons learned to inform maternity care from the UK and Ireland Confidential Enquiries into Maternal Deaths and Morbidity 200914. [Internet]. Oxford: National Perinatal Epidemiology Unit, University of Oxford; 2016 [cited 2018 Oct 25]. Available from: https://www.npeu.ox.ac.uk/downloads/ files/mbrrace-uk/reports/MBRRACEUK\% 20Maternal\%20Report $\% 202016 \% 20-\% 20$ website.pdf

6. Nair S, Dockrell L, MacColgain S. Maternal Early Warning Scores (MEWS) [Internet]. World Federation of Societies of Anesthesiologists; 2018 [cited 2018 Oct 21]. Available from: https://www.wfsahq. org/components/com_virtual_library/media/ d937986303b4f35cdf1b366555ac8f5a383Maternal-Early-Warning-Scores.pdf

7. Friedman A, Campbell M, Kline C, Wiesner S, D'Alton M, Shields L. Implementing Obstetric Early Warning Systems. Am J Perinatol Rep. 2018 Apr;08(02):e79-84.

8. Mhyre JM, D'Oria R, Hameed AB, Lappen JR, Holley SL, Hunter SK, et al. The maternal early warning criteria: a proposal from the national partnership for maternal safety. Obstet Gynecol. 2014 Oct;124(4):782-6.

9. Shields LE, Wiesner S, Klein C, Pelletreau B, Hedriana HL. Use of Maternal Early Warning Trigger tool reduces maternal morbidity. Am J Obstet Gynecol. 2016 Apr;214(4):527.e1527.e6.

10. Singh A, Guleria K, Vaid NB, Jain S. Evaluation of maternal early obstetric warning system (MEOWS chart) as a predictor of obstetric morbidity: a prospective observational study. Eur J Obstet Gynecol Reprod Biol. 2016 Dec;207:11-7. 
11. Edwards SE, Grobman WA, Lappen JR, Winter C, Fox R, Lenguerrand E, et al. Modified obstetric early warning scoring systems (MOEWS): validating the diagnostic performance for severe sepsis in women with chorioamnionitis. Am J Obstet Gynecol. 2015 Apr;212(4):536.e1-8.
12. Carle C, Alexander P, Columb M, Johal J. Design and internal validation of an obstetric early warning score: secondary analysis of the Intensive Care National Audit and Research Centre Case Mix Programme database. Anaesthesia. 2013 Apr;68(4):354-67. 